\title{
Long-Term Monitoring of SARS-COV-2 RNA in Wastewater in Brazil: A More Responsive and Economical Approach
}

leda Carolina Claro

Federal University of ABC

Aline Cabral

Federal University of $A B C$

Matheus Augusto

Federal University of ABC https://orcid.org/0000-0002-0139-1619

Adriana Duran

Federal University of $A B C$

Melissa Cristina Graciosa

Federal University of $A B C$

Fernando Luiz Fonseca

Faculty of Medicine of ABC (FMABC)

Marcia Aparecida Speranca

Federal University of ABC

Rodrigo Bueno ( $\nabla$ rodrigo.bueno@ufabc.edu.br)

Federal University of $A B C$

\section{Article}

Keywords: COVID-19, Wastewater-based epidemiology, SARS-CoV-2, Environmental surveillance, Sewage, Coronavirus

Posted Date: March 24th, 2021

DOl: https://doi.org/10.21203/rs.3.rs-358281/v1

License: (c) (i) This work is licensed under a Creative Commons Attribution 4.0 International License. Read Full License

Version of Record: A version of this preprint was published at Water Research on September 1st, 2021. See the published version at https://doi.org/10.1016/j.watres.2021.117534. 


\section{Abstract}

SARS-CoV-2, the novel Coronavirus, was first detected in Wuhan, China, in December 2019, and has since spread rapidly, causing millions of deaths worldwide. As in most countries of the world, in Brazil, the consequences of the COVID-19 pandemic have been catastrophic. The increasing of deaths and the decrease of available beds in the hospitals, especially in 2021, have disturbed the health authorities. Several studies have reported the fecal shedding of SARS-CoV-2 RNA titers from infected symptomatic and asymptomatic individuals. Therefore, the quantification of SARS-CoV-2 in wastewater can be used to track the virus spread in a population via Wastewater-based Epidemiology (WBE). In this study, samples of untreated wastewater were collected weekly between June 9th, 2020 and March 17th, 2021 (41 weeks) at five sampling sites in the ABC Region, São Paulo, Brazil. This long-term monitoring was performed to evaluate the SARS-CoV-2 occurrence in the sewerage system. SARS-CoV-2 RNA titers were detected throughout the period. The viral RNA concentration ranged from 2.7 to $7.1 \log _{10}$ genome copies. $L^{-1}$, with peaks in the last weeks of monitoring. Furthermore, we observed a positive correlation between the viral load in wastewater samples and the epidemiological/clinical data, with the former preceding the latter by approximately two weeks. The COVID-19 prevalence for each sampling site was estimated using the viral load observed in wastewater and other parameters, via Monte-Carlo simulation. The mean predicted prevalence ranged 0.05 to $0.38 \%$, slightly higher than reported $(0.016 \pm 0.005 \%)$ in the $A B C$ Region for the same period. These results highlight the viability of the WBE approach for COVID-19 infection monitoring in the largest urban agglomeration in South America. Environmental surveillance can be especially useful for health agencies and public decision-makers in predicting SARS-CoV-2 outbreaks, as well as in local tracing of infection clusters.

\section{Background}

Severe acute respiratory syndrome coronavirus-2 (SARS-CoV-2), the etiological agent of Corona Virus Disease 2019 (COVID-19), was first identified in Wuhan, China, in December 2019. Since then, this novel Coronavirus has caused millions of deaths worldwide. The principal symptoms of COVID-19 are dry cough, fever, and difficulty in breathing and the main routes of transmission are through the spread of respiratory droplets, direct contact with infected individuals, and contaminated surfaces ${ }^{1}$.

According to WHO $(2021)^{2}$, until March 21st, 2021, Brazil has registered a total of $11,871,390$ cases of COVID-19 with 290,314 deaths. On March 4th, 2021, the country reached the mark of 1,641 deaths, 46 more than the peak of the "first wave" in July 2020. Since then, the number of deaths has increased, overcoming the mark of 2,000 deaths for several days and reaching the higher mark of 2,841 on March 18th, 2021. Brazil is the country with more deaths reported in 24 hours and the second country with more deaths since the pandemic's beginning. Brazil has administered 13,028,391 vaccine doses until March 19th, 2021, with 9,721,865 people having been vaccinated with at least one dose. However, this last one represents only $4.57 \%$ of all the population. 
On March 21st, 2021, the state of São Paulo has a rate of bed occupancy of $81 \%$ for hospital ward and $91 \%$ for intensive care unit (ICU), a dangerous mark considering the increasing of cases each day. In the metropolitan region of São Paulo, where is located the ABC Region, the rate of bed occupancy is $86.6 \%$ for hospital ward and $91.3 \%$ for ICU (data source: https://www.seade.gov.br/coronavirus/). The severity of the situation highlights the need for alternative techniques for monitoring the virus.

Studies have shown that the SARS-CoV-2 is also shed in feces from infected symptomatic and asymptomatic individuals ${ }^{3}$. Wölfel et al. $(2020)^{4}$ determined a shedding rate greater than $10^{7}$ RNA copies/g feces one week after symptom onset. However, no viable (infective) viral particles were found based on cell cultures. On the other hand, other recent studies have verified the presence of viable particle viral in feces ${ }^{5,6}$.

Several studies have also shown the presence of SARS-CoV-2 in municipal wastewater samples, in The Netherlands ${ }^{7}$, Spain $^{8}$, Australia ${ }^{9}$, USA $^{10}$, Brazil $^{11}$, among other countries. Randazzo et al. $(2020)^{8}$, for example, detected RNA concentrations of $5.4 \pm 0.2 \log _{10}$ genome copies/L on average in the Region of Murcia (Spain). Although the fecal-oral transmission pathway has not been proven, monitoring of wastewater in the sewer network (sewer pipes) and municipal wastewater treatment plants (WWTPS) could support in predicting new SARS-CoV-2 outbreaks, as well as in the local tracing of infection clusters $^{12}$.

Wastewater-Based Epidemiology (WBE) is a methodology originally designed to monitor the use of illicit drugs in a community that now has been applied to COVID-19. Wastewater surveillance data could complement epidemiological/clinical data to provide a robust tool for monitoring the SARS-CoV-2 circulation $7,13,14$. WBE has been successfully used for predicting the outbreak of Aichi virus in The Netherlands ${ }^{15}$ and poliovirus in Israel ${ }^{16}$, and for monitoring the antibiotic resistance on a global scale ${ }^{17}$.

WBE approaches are interesting especially for emerging countries whose capacity for clinical testing is limited. In Brazil, this methodology for tracking the virus spread has been used in the metropolitan region of Rio de Janeiro ${ }^{11}$. As in other countries, the monitoring results have been successfully used as complementary data in the COVID-19 surveillance by the local authorities. However, as attested by Daughton et al. $(2020)^{13}$, the data published so far is insufficient for the WBE methodology implementation. There are many epidemiological (shedding profile of infected individuals, among others) and methodological (sampling strategies and experimental methods) aspects to be elucidated ${ }^{18}$.

In this context, this study aimed to implement a low-cost WEB methodology to monitor the SARS-Cov-2 circulation in vulnerable zones of $A B C$ Region, in Metropolitan Region of Sao Paulo, Brazil. This region has the largest urban agglomeration in South America. This methodology can support decision-making by local health agencies in combating the COVID-19 pandemic.

\section{Results}


SARS-CoV-2 RNA occurrence in wastewater samples. A total of 205 untreated wastewater samples from five points of the ABC Region (São Paulo, Brazil) were analyzed between June 9th, 2020 and March 17th, 2021 (41 weeks) for the SARS-CoV-2 RNA occurrence. Samples with Ct (Cycle threshold) less than 40 were considered positive and had their concentrations determined (genome copies/sample volume), according to Medema et al. $(2020)^{7}$ and Wu et al. $(2020)^{10}$.

Figure 1 shows the $\mathrm{Ct}$ values of the five sampling points for the entire monitoring period.

The RT-qPCR N1 and N2 gene assays were analyzed for all wastewater samples. However, as shown in Fig. 1, there was a higher SARS-CoV-2 occurrence for the N1 target. The SARS-CoV-2 RNA was detected in $40 \%(83 / 205)$ and $29 \%(60 / 205)$ of wastewater samples, for N1 and N2 gene assays, respectively. The differences among N1 and N2 assays on wastewater samples were also reported by other recent studies $^{7,8,10}$. This could be associated with the different analytical sensitivity between the RT-qPCR gene assays $^{8}$. Furthermore, different PCR reactions may not be identically susceptible to the inhibitory effects of the evaluated matrix ${ }^{19}$.

As in this study, Medema et al. (2020) ${ }^{7}$ verified a higher sensitivity for N1 gene assay, detecting SARSCoV-2 RNA titers for a greater number of monitoring points even when clinical data indicated a low prevalence of 1 case per 100,000 inhabitants.

As shown in Fig. 1, the SARS-CoV-2 occurrence in the first weeks was less frequent. However, from November onwards, the SARS-CoV-2 RNA titers were detected in most of the wastewater samples. Coincidentally, at that same time, there were signs of the beginning of a "second wave" and/or recurring local outbreaks of COVID-19 in Brazil ${ }^{20}$. In January, February, and March 2021, the SARS-CoV-2 RNA was detected in $91 \%$ (10/11), 100\% (11/11), 82\% (9/11), 64\% (7/11), and 82\% (9/11) of the wastewater samples from points $1,2,3,4$ and 5 , respectively, clearly indicating the late spread of SARS-CoV-2 in the $A B C$ Region.

Figure 2 shows the Box Plot of the SARS-CoV-2 viral load (N1 assay) per sampling point for the entire monitoring period.

There were no statistical differences among the mean SARS-CoV-2 RNA concentrations, as determined by the one-way analysis of variance (ANOVA), considering a significance level of 0.05 . The mean concentrations were $5.1 \pm 1.2,5.2 \pm 1.0,5.3 \pm 1.2,5.4 \pm 1.6$, and $4.9 \pm 0.9 \log _{10}$ genome copies. $L^{-1}$ for points $1,2,3,4$ and 5 , respectively.

The average SARS-CoV-2 RNA titers in wastewater samples were equivalent to those detected by Randazzo et al. $(2020)^{8}$ in Spain, about $5.1 \pm 0.3 \log _{10}$ genome copies. $L^{-1}$ for the $N 1$ assay. Similarly, Wu et al. $(2020)^{10}$ detected a viral load between 4 and $5 \log _{10}$ genome copies.L-1 ${ }^{-1}$, but in Massachusetts, USA. 
The maximum and minimum values of SARS-CoV-2 RNA found in this study were 7.1 and $2.7 \log _{10}$ genome copies. $\mathrm{L}^{-1}$, respectively, considering the entire data set. Other studies have also observed this wide range of concentrations. Wurtzer et al. $(2020)^{21}$, for example, detected a viral load between 4 and 7 $\log _{10}$ genome copies.L $L^{-1}$, in France. Gonzales et al. (2020) ${ }^{22}$ detected values between 2 and $5 \log _{10}$ genome copies. $\mathrm{L}^{-1}$, in Virginia, USA. According to Prado et al. $(2021)^{11}$, different factors can influence the viral load determination, including the circumstances of the COVID-19 pandemic experienced in each region. Besides, we believe that the specificities of the sewage and the sewer network in each region also affect the experimental determinations. In Brazil, sewage, and surface run-off (rainwater and stormwater) are collected separately. However, there is a high rate of clandestine connections to the sewer network, which promotes the dilution of sewage during rainy events.

Therefore, the viral load measured in the wastewater samples from the ABC Region was consistent with those found in other studies around the world.

Environmental surveillance. Supplementary Fig. 1 shows the spread of the SARS-CoV-2 in the ABC region for different dates, considering the viral load measured (N1 assay) in the wastewater samples.

As observed in Supplementary Fig. 1, the SARS-CoV-2 RNA concentration from all sampling sites increased gradually over time, indicating the spread of COVID-19 infection in the ABC Region. At the beginning of monitoring (June 2020), the amount of SARS-CoV-2 RNA titers in wastewater samples were much less expressive than those found in the last weeks. As previously shown, this behavior was also observed for the Ct results (Fig. 1).

The presentation of monitoring results through heat maps (Supplementary Fig. 1) can be especially useful for health agencies since it allows the spatial analysis of the pandemic situation.

Epidemiological/clinical data on COVID-19 in the ABC Region was obtained from the publicly available repository of the Federal University of $A B C$, "Onde tem coronavirus?" project (available at https://ondetemcoronavirus.ufabc.edu.br/). Figure 3 shows the new cases during the monitoring period normalized by each city's population. The cumulative prevalence of COVID-19 (in percentage), considering all municipalities of the ABC Region, was also plotted.

As shown in Fig. 3, although there is a wide variability of data, an upward trend of COVID-19 cases in the ABC Region can be observed, especially from November onwards. As previously discussed, the SARSCoV-2 occurrences in wastewater samples showed the same behavior (Fig. 2).

Figure 4 shows the SARS-CoV-2 viral load (N1 assay) in the five sampling points throughout the monitoring period.

Despite the relatively large variance, an upward trend in SARS-CoV-2 viral load (red arrow) was observed for the five monitoring points (Fig. 4), following the continuous increase of reported clinical cases (Fig. 3). Therefore, there is a correlation between the amount of SARS-CoV-2 in wastewater and the 
hospitalization data, as observed by other authors $7,11,23,24$. However, few studies have reported long-term monitoring (over several months) of SARS-CoV-2 in wastewater ${ }^{11,25}$. A large dataset allows for more robust statistical analysis and, therefore a more reliable model for $\mathrm{WBE}^{13}$.

Figure 5 shows the SARS-CoV-2 amount (N1 assay) for samples of Point 1 (WWTP ABC) in relation to the number of new COVID-19 cases of ABC Region. The temporal delay between the SARS-CoV-2 RNA peaks (for wastewater samples) and clinical data are indicated with black arrows. Point 1 was chosen for this comparative analysis, since it receives most of the wastewater generated in the $A B C$ region and, therefore is the most representative monitoring point.

As observed in Fig. 5, there is a correlation between the SARS-CoV-2 amount variation in wastewater and the clinical data on COVID-19 with the former preceding the latter by approximately 14 days (two weeks). These results are consistent since the transmission of SARS-CoV-2 generally precedes the notification of a positive test by 2 to 3 weeks. This time interval corresponds to an incubation period between 2 and 14 days followed by clinical testing about a week after symptoms onset ${ }^{25-27}$.

Other studies have observed the same behavior ${ }^{7,25,27-30}$. Saguti et al. $(2021)^{25}$, for example, verified peaks of SARS-CoV-2 in wastewater samples from a WWTP in Sweden occurring 3 to 4 weeks before clinical notification. Ahmed et al. $(2021)^{28}$, detected SARS-CoV-2 in wastewater samples from three WWTPs in Australia up to 3 weeks before the first reported clinical case. Peccia et al. $(2020)^{27}$, observed a shorter delay of about a week when analyzing samples of primary sludge from a WWTP in USA.

In Florianopolis (Santa Catarina, Brazil), the viral genome of SARS-CoV-2 was detected in wastewater samples in November 2019, before the first case in the Americas was reported. The SARS-CoV-2 occurrence was confirmed by genome sequencing analysis. The mean concentration was $5.83 \pm 0.12$ $\log _{10}$ genome copies. $L^{-1}$, while the maximum and minimum values were $6.68 \pm 0.02$ and $5.49 \pm 0.02$ $\log _{10}$ genome copies.L $L^{-1}$, respectively ${ }^{31}$.

These results indicate that wastewater surveillance can be used successfully as an early warning system for monitoring COVID-19. This methodology allows verifying the increase or reduction in the number of active cases about 2 weeks in advance. In addition, since the monitoring can be regionalized by sewer sub-basins, control actions by health agencies can be directed to the infection and transmission clusters.

Prevalence estimate. The COVID-19 prevalence for each sampling site, shown in Table 1, was estimated using the SARS-CoV-2 RNA titers data (N1 assay) and other parameters (methods: equations 1 and 2). The positive results (for SARS-CoV-2 occurrence) of all monitoring weeks were considered. The predicted prevalence of COVID-19, resulting from the Monte-Carlo simulation, was summarized in Table 1 as mean and $95 \%$ confidence interval $(\mathrm{Cl})$ (lower and upper). 
Table 1

Predicted prevalence of COVID-19 for each sampling point.

\begin{tabular}{|llll|}
\hline Sampling point & Mean & \multicolumn{2}{l|}{ 95\% Confidence Interval } \\
\cline { 3 - 4 } & (\%) & Lower (\%) & Upper (\%) \\
\hline Point 1: & 0.20 & 0.05 & 2.10 \\
WWTP ABC & & & \\
\hline $\begin{array}{l}\text { Point 2: } \\
\text { Vila Vilma }\end{array}$ & 0.19 & 0.05 & 2.16 \\
\hline $\begin{array}{l}\text { Point 3: } \\
\text { Califórnia Paulista }\end{array}$ & 0.23 & 0.06 & 2.61 \\
\hline $\begin{array}{l}\text { Point 4: } \\
\text { Parque Indaiá }\end{array}$ & 0.38 & 0.10 & 4.39 \\
\hline $\begin{array}{l}\text { Point 5: } \\
\text { WTTP Parque Andreense }\end{array}$ & & & \\
\hline
\end{tabular}

The average prevalence (in percentage) in the ABC Region for the same period (June 9th, 2020 - March 17th, 2021) was $0.016 \pm 0.005 \%$. As shown in Table 1, the predicted values were much higher (about 10 times) than the observed COVID-19 prevalence (considering epidemiological/clinical data).

Wu et al. (2020) ${ }^{10}$, also estimated prevalence values (0.1-5\%) higher than those reported (about $0.026 \%$ ) in Massachusetts, USA.

\section{Discussion}

In this study, a long-term monitoring of SARS-CoV-2 occurrence in wastewater samples was performed. Five sampling sites in the ABC Region (São Paulo, Brazil) were evaluated. The viral RNA concentration ranged from 2.7 to $7.1 \log _{10}$ genome copies. $L^{-1}$, with peaks being detected in the last weeks of monitoring. We observed a positive correlation between the viral load in wastewater samples and the epidemiological/clinical data, with the former preceding the latter by approximately two weeks.

The long-term monitoring (41 weeks) allowed to assess different moments of the pandemic in the studied area, such as the increase in cases of COVID-19 in the first months of 2021, the worst period of the pandemic in the ABC Region.

Although the WBE approach emerges as a promising and attractive tool for epidemiological surveillance, there are still some challenges to be considered. Some factors that influence the prevalence estimation model. 
The municipal wastewater is a complex matrix with different chemical (organic and inorganic) and biological compounds. In general, it provides a lot of information about the habits and characteristics of a population. However, some of its constituents may contribute to the degradation of SARS-CoV-2 RNA $^{18,32}$. Bivins et al. $(2020)^{33}$, observed a time for $90 \%$ reduction $\left(T_{90}\right)$ of viable SARS-CoV- 2 in untreated wastewater about 26.2 days at $20^{\circ} \mathrm{C}$. Ahmed et al. $(2020)^{34}$, verified a $\mathrm{T}_{90}$ of 20.4 and 12.6 days at 15 and $25^{\circ} \mathrm{C}$, respectively. As expected, the decay rate increases as the temperature also increase.

Although the wastewater residence times in the sewer network are not so long, the effect of degradation must be considered, especially in warm climate regions ${ }^{18}$. Furthermore, sampling sites that represent large areas and basins, such as the WWTP points, are more susceptible to the degradation effect of the viral genome during wastewater travel.

There are discrepancies regarding viral shedding by humans. Some studies have indicated that only $60-$ $70 \%$ of infected individuals shed SARS-CoV-2 RNA titers ${ }^{10,25,35}$. On the other hand, other studies have already proved that asymptomatic and undiagnosed carriers also shedding SARS-CoV-2 RNA titers 3,36,37. There are also discrepancies in the viral load excreted by an infected individual. Wölfel et al. $(2020)^{4}$ observed a shedding rate between 2.56 and $7.67 \log _{10}$ genome copies.g feces ${ }^{-1}$. The shedding rates reported by Kitajima et al. $(2020)^{3}$ range from 5.79 to $8.11 \log _{10}$ genome copies.g feces ${ }^{-1}$. There is still a great variation in the mass of feces eliminated by each infected individual, as previously discussed.

Another important aspect is the time that an infected individual remains to eliminate the SARS-CoV-2 RNA titers. Zheng et al. (2020) ${ }^{35}$ observed that the SARS-CoV-2 duration in feces samples is significantly longer than in serum and respiratory samples. The average duration of the virus in feces samples was 22 days (interquartile range from 17 to 31 days), while in respiratory and serum samples were 18 and 16 days, respectively. Thus, an infected individual remains to eliminate the virus even when it is no longer considered an active case.

In addition to the above-mentioned factors, there are still limitations and uncertainty in the sampling strategies, and in the methods of concentration, extraction, and quantification of SARS-CoV-2 RNA ${ }^{13,18}$.

Therefore, an absolute comparison between the observed COVID-19 prevalence and the SARS-CoV-2 RNA concentrations in wastewater is significantly complex. On other hand, as also attested by Medema et al. $(2020)^{7}$, the epidemiological surveillance based on relative changes in SARS-CoV-2 RNA titers from wastewater samples of sewer pipes and WWTP over time can be used as an additional monitoring tool capable of providing an early warning of SARS-CoV-2 circulation. The WBE is especially useful for health agencies and public decision-makers and should be incorporated in the country's epidemiological surveillance and public policy development. This research is a step towards the improvement of WBE to track COVID-19.

\section{Methods}


Sampling sites and samples collection. Untreated wastewater from five points of the ABC Region, São Paulo, Brazil, was collected and analyzed for 41 weeks, between June 9th, 2020 and March 17th, 2021, for the SARS-CoV-2 RNA occurrence. All monitored points are shown in Supplementary Fig. 2.

Additional information on sampling points is shown in Supplementary Table 1.

The sampling points represent the different income levels in the region. Besides, there are also differences in the level of urbanization, access to basic sanitation, and the flow of wastewater generated.

In the WWTPs (points 1 and 5), 24-hour composite sampling of $1000 \mathrm{~mL}$ (proportional to the hourly flow rate) was performed using a refrigerated Hach automatic sampler (model AWRS AS950), with a storage temperature of $4^{\circ} \mathrm{C}$. In the sewer pipes (points 2, 3, and 4), 4-hour semi-composite sampling (proportional to the hourly flow rate) was carried out using the same automatic sampler. These sampling strategies allow a greater representation of the wastewater characteristics. The sampling frequency was weekly at all monitoring sites.

Wastewater concentration and RNA extraction. Before the concentration step, wastewater samples were pasteurized at $60^{\circ} \mathrm{C}$ for 90 minutes to inactivate the virus, according to Wu et al. (2020) ${ }^{10}$. Viral particles were concentrated by the precipitation method, as described by Wu et al. (2020) ${ }^{10}$. Briefly, $40 \mathrm{~mL}$ of composite samples were centrifuged at $8000 \mathrm{xg}$ for $120 \mathrm{~min}$ at $4^{\circ} \mathrm{C}$ and the pellet was resuspended in 0,4 $\mathrm{mL}$ of $1 \times$ PBS (pH 7.2). For sample cleaning, $1 \mathrm{~mL}$ of acid phenol was added and mixed strongly (Cabral et al. 2020) ${ }^{38}$. An aqueous phase was then formed by centrifugation at $12.000 \mathrm{xg}$ for $10 \mathrm{~min}$ and transferred to a microtube containing $0.3 \mathrm{~mL}$ of lysis buffer. RNA extraction was performed using the PureLink $^{\text {TM }}$ Viral RNA/DNA Mini Kit (Thermo Fisher Scientific), according to the manufacturer's protocol. The concentration of RNA was measured in the Nanodrop Lite (Thermo Fisher Scientific). The enveloped bovine respiratory syncytial virus (BRSV - Inforce ${ }^{\mathrm{TM}} 3$, Zoetis, US) was used for evaluated concentration methods recovery capacity.

Viral detection and quantification. The presence of RNA SARS-CoV-2 was determined using the 2019nCoV TaqMan RT-PCR Kit (Norgen, Cat. TM67120) based on the assays and protocols developed by the Centers for Disease Control and Prevention (CDC). The RT-qPCR was carried out following the manufacturer's instructions, recommended standards, and positive controls in a Rotor-Gene Q (Qiagen) instrument. Each RNA extract was analyzed in duplicate. A calibration curve was performed using the 2019-nCoV_N_Positive Control (Norgen, Cat. PC67102). Reactions were performed in a final volume of 20 $\mu \mathrm{L}$, using $5 \mu \mathrm{L}$ of the extracted RNA, $10 \mu \mathrm{L}$ of 2x One-Step RT-PCR Master Mix, $1.5 \mu \mathrm{L}$ of Primer\&Probe Mix, and 3.5 $\mu \mathrm{L}$ of RNAse free water. A series of positive (four 10 -fold serial dilutions) and negative controls (extraction and PCR) were included for each RT-qPCR run by N1 and N2 genome target. The cycling program followed: cycle $1-50^{\circ} \mathrm{C}$ for 30 minutes; cycle $2-95^{\circ} \mathrm{C}$ for 3 minutes; cycle $3-45 \times 95^{\circ} \mathrm{C}$ for 3 seconds and $55^{\circ} \mathrm{C}$ for 30 seconds (acquiring fluorescence in the green filter, as the probes contain FAM fluorescence). Cycle threshold (Ct) values were used to calculate $\mathrm{GC} / \mathrm{L}$ in the original sample. $\mathrm{Ct}$ values lower than 40 were considered positive for SARS-CoV-2, as proposed previously ${ }^{7,10}$. BRSV RT- qPCR 
reactions were performed according to previous protocols described by Rajal et al. (2007) ${ }^{39}$ and Boxus et al. $(2005)^{40}$.

Prevalence estimation. The infected population in the ABC Region was estimated using the SARS-CoV- 2 viral load measured in wastewater and other parameters, according to the following Eq. 9,23:

Infected population $(N)=\frac{C_{R N A} \times F}{\alpha \times \beta}$

Where:

$\mathrm{C}_{\mathrm{RNA}}=\mathrm{SARS}-\mathrm{CoV}-2$ RNA concentration measured in wastewater samples (genome copies. $\mathrm{L}^{-1}$ ).

$F=$ Wastewater volumetric flow rate $\left(L \cdot d^{-1}\right)$.

$a=$ Fecal load (g.person $\left.{ }^{-1} \cdot d^{-1}\right)$.

$\beta=$ SARS-CoV-2 shedding rate by an infected individual (genome copies. $\mathrm{g}^{-1}$ ).

The SARS-CoV-2 RNA titers in wastewater $\left(\mathrm{C}_{\mathrm{RNA}}\right)$ were measured for the five monitoring points in the $A B C$ Region, as previously described.

In the WWTPs (points 1 and 5), the wastewater volumetric flow rate $(F)$ was measured in loco, while for the sewer pipes points (points 2,3, and 4), it was estimated from the per capita wastewater generation (160 L.person $\left.{ }^{-1} \cdot d^{-1}\right)$ and the contributing population (Supplementary Table 1).

The daily feces mass (a) produced by humans from low-income countries usually ranges from 75 to 520 grams per person (with an average value of $149 \pm 95$ g.person ${ }^{-1} \cdot d^{-1}$ ), according to Rose et al. $(2015)^{41}$.

The SARS-CoV-2 shedding rate by an infected individual $(\beta)$ usually ranges from $6.3 \times 10^{5}$ to $1.3 \times 10^{8}$ genome copies. $\mathrm{g}^{-1}$, according to Kitajima et al. (2020) ${ }^{3}$ and Gholipour et al. (2021) ${ }^{42}$.

Thus, the COVID-19 average prevalence was estimated for each sampling site considering the contributing population (Supplementary Table 1), according to the following equation:

Predicted prevalence $(\%)=\frac{\mathrm{N}}{\text { Contributing population }} \times 100$

Statistical analysis. The one-way analysis of variance (ANOVA) was used to determine whether there were differences among the mean SARS-CoV-2 RNA concentrations of each sampling site, considering a significance level of 0.05 . 
The statistical Monte-Carlo approach was incorporated into the calculation of the prevalence estimate (Equations 1 and 2), since parameters such as Fecal load (a) and SARS-CoV-2 shedding rate ( $\beta$ ) have large variation, which makes it difficult to interpret the results of the infected population $(\mathrm{N})$ and, consequently, the predicted prevalence. Monte-Carlo simulation with 10,000 random samplings from each parameter/input of Eq. 1 was implemented. The parameters values and their respective types of statistical distribution were shown in Supplementary Table 2. The Monte-Carlo simulation summary was reported as mean and $95 \%$ confidence interval $(\mathrm{Cl})$ for each sampling point.

Statistical analysis was performed using Origin Pro, while the Monte-Carlo simulation was implemented in Microsoft Excel.

\section{Declarations}

\section{Acknowledgments}

The authors would like to acknowledge the financial support from the following Brazilian institutions: Brazilian National Council of Scientific and Technological Development (CNPq) in partnership with Ministry of Science, Technology, Innovations and Communications (MCTIC), and Ministry of Health (MS), Secretariat of Science, Technology, Innovation and Strategic Inputs - Decit/SCTIE 07/2020 (Research to cope with COVID-19, its consequences and other severe acute respiratory syndromes - Process Number 402432/2020-7).

\section{Author Contributions}

leda Carolina Mantovani Claro: Conceptualization, Methodology, Formal analysis, Investigation, Writing. Aline Diniz Cabral: Conceptualization, Methodology, Formal analysis, Investigation, Writing. Matheus Ribeiro Augusto: Methodology, Formal analysis, Investigation, Writing. Adriana Feliciano Alves Duran: Methodology, Formal analysis, Investigation, Writing. Melissa Cristina Pereira Graciosa: Resources, Writing. Fernando Luiz Affonso Fonseca: Resources, Writing. Marcia Aparecida Speranca: Resources, Writing. Rodrigo de Freitas Bueno: Resources, Supervision, Project administration, Funding acquisition, Conceptualization.

\section{Competing Interests Statements}

The authors declare no conflicts of interest.

\section{References}

1. WHO. Coronavirus disease (COVID-19) pandemic. World Health Organization https://www.who.int/emergencies/diseases/novel-coronavirus-2019 (2021).

2. WHO. Coronavirus (COVID-19) Dashboard. World Health Organization https://covid19.who.int/ (2021). 
3. Kitajima, M. et al. SARS-CoV-2 in wastewater: State of the knowledge and research needs. Sci. Total Environ. 739, 139076 (2020).

4. Wölfel, R. et al. Virological assessment of hospitalized patients with COVID-2019. Nature 581, 465469 (2020).

5. Wang, W. et al. Detection of SARS-CoV-2 in Different Types of Clinical Specimens. JAMA 323, 18431844 (2020).

6. Xiao, F. et al. Evidence for Gastrointestinal Infection of SARS-CoV-2. Gastroenterology 158, 18311833.e3 (2020).

7. Medema, G., Heijnen, L., Elsinga, G., Italiaander, R. \& Brouwer, A. Presence of SARS-Coronavirus-2 RNA in Sewage and Correlation with Reported COVID-19 Prevalence in the Early Stage of the Epidemic in The Netherlands. Environ. Sci. Technol. Lett. 7, 511-516 (2020).

8. Randazzo, W. et al. SARS-CoV-2 RNA in wastewater anticipated COVID-19 occurrence in a low prevalence area. Water Res. 181, 115942 (2020).

9. Ahmed, W. et al. First confirmed detection of SARS-CoV-2 in untreated wastewater in Australia: A proof of concept for the wastewater surveillance of COVID-19 in the community. Sci. Total Environ. 728,138764 (2020).

10. Wu, F. et al. SARS-CoV-2 Titers in Wastewater Are Higher than Expected from Clinically Confirmed Cases. mSystems 5, 1-9 (2020).

11. Prado, T. et al. Wastewater-based epidemiology as a useful tool to track SARS-CoV-2 and support public health policies at municipal level in Brazil. Water Res. 191, 116810 (2021).

12. Thompson, J. R. et al. Making waves: Wastewater surveillance of SARS-CoV-2 for population-based health management. Water Res. 184, 116181 (2020).

13. Daughton, C. G. Wastewater surveillance for population-wide Covid-19: The present and future. Sci. Total Environ. 736, 139631 (2020).

14. Larsen, D. A. \& Wigginton, K. R. Tracking COVID-19 with wastewater. Nat. Biotechnol. 38, 1151-1153 (2020).

15. Lodder, W. J., Rutjes, S. A., Takumi, K. \& Husman, A. M. de R. Aichi Virus in Sewage and Surface Water, the Netherlands. Emerg. Infect. Dis. 19, 1222-1230 (2013).

16. Brouwer, A. F. et al. Epidemiology of the silent polio outbreak in Rahat, Israel, based on modeling of environmental surveillance data. Proc. Natl. Acad. Sci. 115, E10625-E10633 (2018).

17. Hendriksen, R. S. et al. Global monitoring of antimicrobial resistance based on metagenomics analyses of urban sewage. Nat. Commun. 10, 1124 (2019).

18. Zhu, Y. et al. Early warning of COVID-19 via wastewater-based epidemiology: potential and bottlenecks. Sci. Total Environ. 767, 145124 (2021).

19. Bustin, S. A. et al. The MIQE guidelines: Minimum information for publication of quantitative realtime PCR experiments. Clin. Chem. 55, 611-622 (2009). 
20. Sabino, E. C. et al. Resurgence of COVID-19 in Manaus, Brazil, despite high seroprevalence. Lancet 397, 452-455 (2021).

21. Wurtzer, S. et al. Evaluation of lockdown effect on SARS-CoV-2 dynamics through viral genome quantification in waste water, Greater Paris, France, 5 March to 23 April 2020. Eurosurveillance 25, (2020).

22. Gonzalez, R. et al. COVID-19 surveillance in Southeastern Virginia using wastewater-based epidemiology. Water Res. 186, 116296 (2020).

23. Saththasivam, J. et al. COVID-19 (SARS-CoV-2) outbreak monitoring using wastewater-based epidemiology in Qatar. Sci. Total Environ. 774, 145608 (2021).

24. Miyani, B., Fonoll, X., Norton, J., Mehrotra, A. \& Xagoraraki, I. SARS-CoV-2 in Detroit Wastewater. J. Environ. Eng. 146, 06020004 (2020).

25. Saguti, F. et al. Surveillance of wastewater revealed peaks of SARS-CoV-2 preceding those of hospitalized patients with COVID-19. Water Res. 189, 116620 (2021).

26. $\mathrm{Bi}, \mathrm{Q}$. et al. Epidemiology and transmission of COVID-19 in 391 cases and 1286 of their close contacts in Shenzhen, China: a retrospective cohort study. Lancet Infect. Dis. 20, 911-919 (2020).

27. Peccia, J. et al. Measurement of SARS-CoV-2 RNA in wastewater tracks community infection dynamics. Nat. Biotechnol. 38, 1164-1167 (2020).

28. Ahmed, W. et al. SARS-CoV-2 RNA monitoring in wastewater as a potential early warning system for COVID-19 transmission in the community: A temporal case study. Sci. Total Environ. 761, 144216 (2021).

29. Nemudryi, A. et al. Temporal Detection and Phylogenetic Assessment of SARS-CoV-2 in Municipal Wastewater. Cell Reports Med. 1, 100098 (2020).

30. La Rosa, G. et al. First detection of SARS-CoV-2 in untreated wastewaters in Italy. Sci. Total Environ. 736, 139652 (2020).

31. Fongaro, G. et al. The presence of SARS-CoV-2 RNA in human sewage in Santa Catarina, Brazil, November 2019. Sci. Total Environ. 778, 146198 (2021).

32. Mao, K. et al. The potential of wastewater-based epidemiology as surveillance and early warning of infectious disease outbreaks. Curr. Opin. Environ. Sci. Heal. 17, 1-7 (2020).

33. Bivins, A. et al. Persistence of SARS-CoV-2 in Water and Wastewater. Environ. Sci. Technol. Lett. 7, 937-942 (2020).

34. Ahmed, W. et al. Decay of SARS-CoV-2 and surrogate murine hepatitis virus RNA in untreated wastewater to inform application in wastewater-based epidemiology. Environ. Res. 191, 110092 (2020).

35. Zheng, S. et al. Viral load dynamics and disease severity in patients infected with SARS-CoV-2 in Zhejiang province, China, January-March 2020: retrospective cohort study. BMJ 369, m1443 (2020).

36. Chavarria-Miró, G. et al. Time Evolution of Severe Acute Respiratory Syndrome Coronavirus 2 (SARSCoV-2) in Wastewater during the First Pandemic Wave of COVID-19 in the Metropolitan Area of 
Barcelona, Spain. Appl. Environ. Microbiol. 87, 1-9 (2021).

37. Jiang, X. et al. Asymptomatic SARS-CoV-2 infected case with viral detection positive in stool but negative in nasopharyngeal samples lasts for 42 days. J. Med. Virol. 92, 1807-1809 (2020).

38. Cabral, A. D. et al. Standardization of the method of concentration and extraction of nucleic acids in wastewater samples: A low-cost tool for use in a surveillance SARS-CoV-2. Eng. Sanit. e Ambient. 1, 1-17 (2020).

39. Rajal, V. B. et al. Validation of hollow fiber ultrafiltration and real-time PCR using bacteriophage PP7 as surrogate for the quantification of viruses from water samples. Water Res. 41, 1411-1422 (2007).

40. Boxus, M., Letellier, C. \& Kerkhofs, P. Real Time RT-PCR for the detection and quantitation of bovine respiratory syncytial virus. J. Virol. Methods 125, 125-130 (2005).

41. Rose, C., Parker, A., Jefferson, B. \& Cartmell, E. The Characterization of Feces and Urine: A Review of the Literature to Inform Advanced Treatment Technology. Crit. Rev. Environ. Sci. Technol. 45, 18271879 (2015).

42. Gholipour, S. et al. COVID-19 infection risk from exposure to aerosols of wastewater treatment plants. Chemosphere 273, 129701 (2021).

\section{Figures}


(a)

\begin{tabular}{|c|c|c|c|c|c|c|c|c|c|c|c|c|c|}
\hline Day of collection: & $20 / 6 / 9$ & \begin{tabular}{|l|}
$20 / 6 / 16$ \\
\end{tabular} & $20 / 6 / 23$ & \begin{tabular}{|l|}
$20 / 6 / 30$ \\
\end{tabular} & $20 / 7 / 7$ & $20 / 7 / 14$ & $\mid 20 / 7 / 21$ & $20 / 7 / 28$ & $20 / 8 / 4$ & $20 / 8 / 11$ & $20 / 8 / 18$ & $20 / 8 / 25$ & $20 / 9 / 1$ \\
\hline Point 1: WWTP ABC & & & & & & & a & 0 & & (ik & & & \\
\hline Point 2: Vila Vilma & & & & & & $\theta k$ & 0 & 0 & & 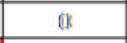 & & & \\
\hline Point 3: C. Paulista & & & & & & $\theta k$ & 0 & 0 & & 0 & & & \\
\hline Point 4: P. Indaiá & & & & & & 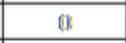 & 0 & 0 & & 6 & & & \\
\hline Point 5: WWTP P.A. & & & & & & 6 & 0 & & & 6 & & & \\
\hline Day of collection: & 20/9/15 & 20/9/22 & $20 / 9 / 29$ & $20 / 10 / 6$ & 20/10/13 & $20 / 10 / 20$ & 20/10/27 & $20 / 11 / 5$ & $20 / 11 / 20$ & 20/11/24 & 20/12/1 & $20 / 12 / 8$ & 20/12/15 \\
\hline \multirow{2}{*}{\multicolumn{14}{|c|}{$\begin{array}{l}\text { Point 1: WWTP ABC } \\
\text { Point 2: Vila Vilma }\end{array}$}} \\
\hline & & & & & & & & & & & & & \\
\hline \multicolumn{14}{|l|}{ Point 3: C. Paulista } \\
\hline \multicolumn{14}{|l|}{ Point 4: P. Indaiá } \\
\hline \multicolumn{14}{|l|}{ Point 5: WWTP P.A. } \\
\hline Day of collection: & 20/12/22 & 20/12/29 & $21 / 1 / 5$ & 21/1/13 & $21 / 1 / 20$ & $21 / 1 / 27$ & $21 / 2 / 3$ & $21 / 2 / 10$ & $21 / 2 / 17$ & $21 / 2 / 24$ & $21 / 3 / 3$ & $21 / 3 / 10$ & 21/3/17 \\
\hline \multicolumn{14}{|l|}{ Point 1: WWTP ABC } \\
\hline \multirow{2}{*}{\multicolumn{14}{|c|}{\begin{tabular}{|l|} 
Point 2: Vila Vilma \\
Point 3: C. Paulista \\
\end{tabular}}} \\
\hline \multirow{2}{*}{\multicolumn{14}{|c|}{ Point 3: C. Paulista }} \\
\hline Point 4: P. Indaiá & & & & & & & & & & & & & \\
\hline Point 5: WWTP P.A. & & & & & & & & & & & & & \\
\hline
\end{tabular}

Point 5: WWTP PA.

(b) Day of collection:

\begin{tabular}{|c|c|c|c|c|c|c|c|c|c|c|c|c|c|}
\hline Day of collection: & $20 / 6 / 9$ & 20/6/16 & $20 / 6 / 23$ & $20 / 6 / 30$ & $20 / 7 / 7$ & $20 / 7 / 14$ & $20 / 7 / 21$ & $20 / 7 / 28$ & $20 / 8 / 4$ & 20/8/11 & 20/8/18 & $20 / 8 / 25$ & 20/9/1 \\
\hline Point 1: WWTP ABC & & & & & & & & & & 6 & & & \\
\hline Point 2: Vila Vilma & & & & & & & & & & 0 & & & \\
\hline Point 3: C. Paulista & & & & & & & & & & $\theta_{k}$ & & & \\
\hline Point 4: P. Indaiá & & & & & & & & & & 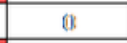 & & & \\
\hline Point 5: WWTP P.A. & & & & & & & & & & 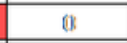 & & & \\
\hline Day of collection: & 20/9/15 & 20/9/22 & 20/9/29 & 20/10/6 & 20/10/13 & 20/10/20 & 20/10/27 & $20 / 11 / 5$ & $20 / 11 / 20$ & 20/11/24 & 20/12/1 & $20 / 12 / 8$ & 20/12/15 \\
\hline \multirow{2}{*}{\multicolumn{14}{|c|}{$\begin{array}{l}\text { Point 1: WWTP ABC } \\
\text { Point 2: Vila Vilma }\end{array}$}} \\
\hline & & & & & & & & & & & & & \\
\hline \multicolumn{14}{|l|}{ Point 3: C. Paulista } \\
\hline \multicolumn{14}{|l|}{ Point 4: P. Indaiá } \\
\hline \multicolumn{14}{|l|}{ Point 5: WWTP P.A. } \\
\hline Day of collection: & 20/12/22 & 20/12/29 & $21 / 1 / 5$ & 21/1/13 & $21 / 1 / 20$ & 21/1/27 & $21 / 2 / 3$ & $21 / 2 / 10$ & $21 / 2 / 17$ & 21/2/24 & $21 / 3 / 3$ & $21 / 3 / 10$ & $21 / 3 / 17$ \\
\hline \multirow{2}{*}{\multicolumn{14}{|c|}{ Point 1: WWTP ABC }} \\
\hline \multirow{2}{*}{\multicolumn{14}{|c|}{$\begin{array}{l}\text { Point 2: Vila Vilma } \\
\text { Point 3: C. Paulista }\end{array}$}} \\
\hline & & & & & & & & & & & & & \\
\hline \multicolumn{14}{|l|}{ Point 4: P. Indaiá } \\
\hline Point 5: WWTP P.A. & & & & & & & & & & & & & \\
\hline
\end{tabular}

Ct scale:

\begin{tabular}{|l|l|l|l|}
\hline $34-36$ & $37-39$ & $40-42$ & $>43$ \\
\hline
\end{tabular}

Figure 1

Ct values: SARS-CoV-2 occurrence for RT-qPCR N1 (a) and N2 (b) gene assays. 


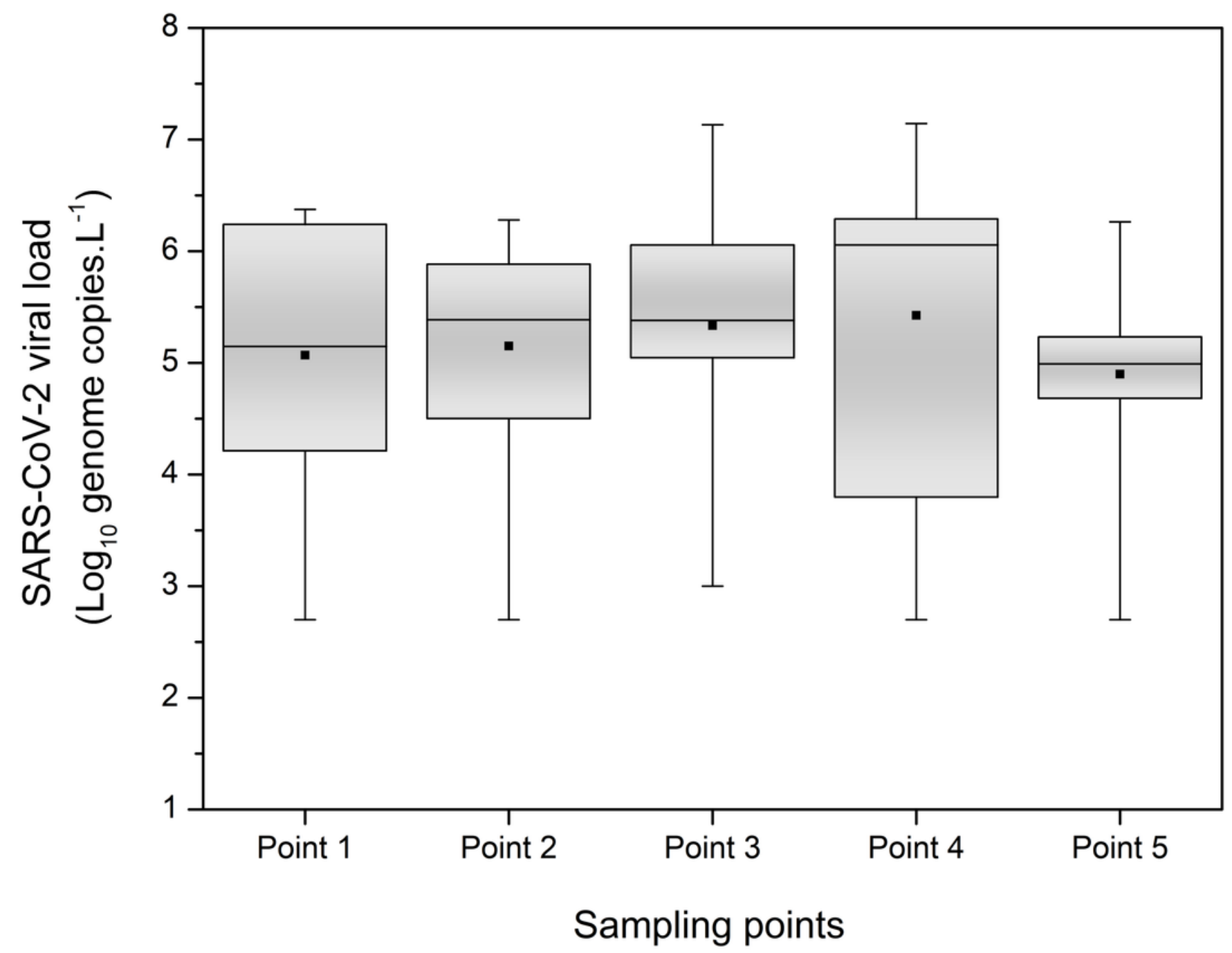

Figure 2

Box Plot of the SARS-CoV-2 viral load (N1 assay) per sampling point. 


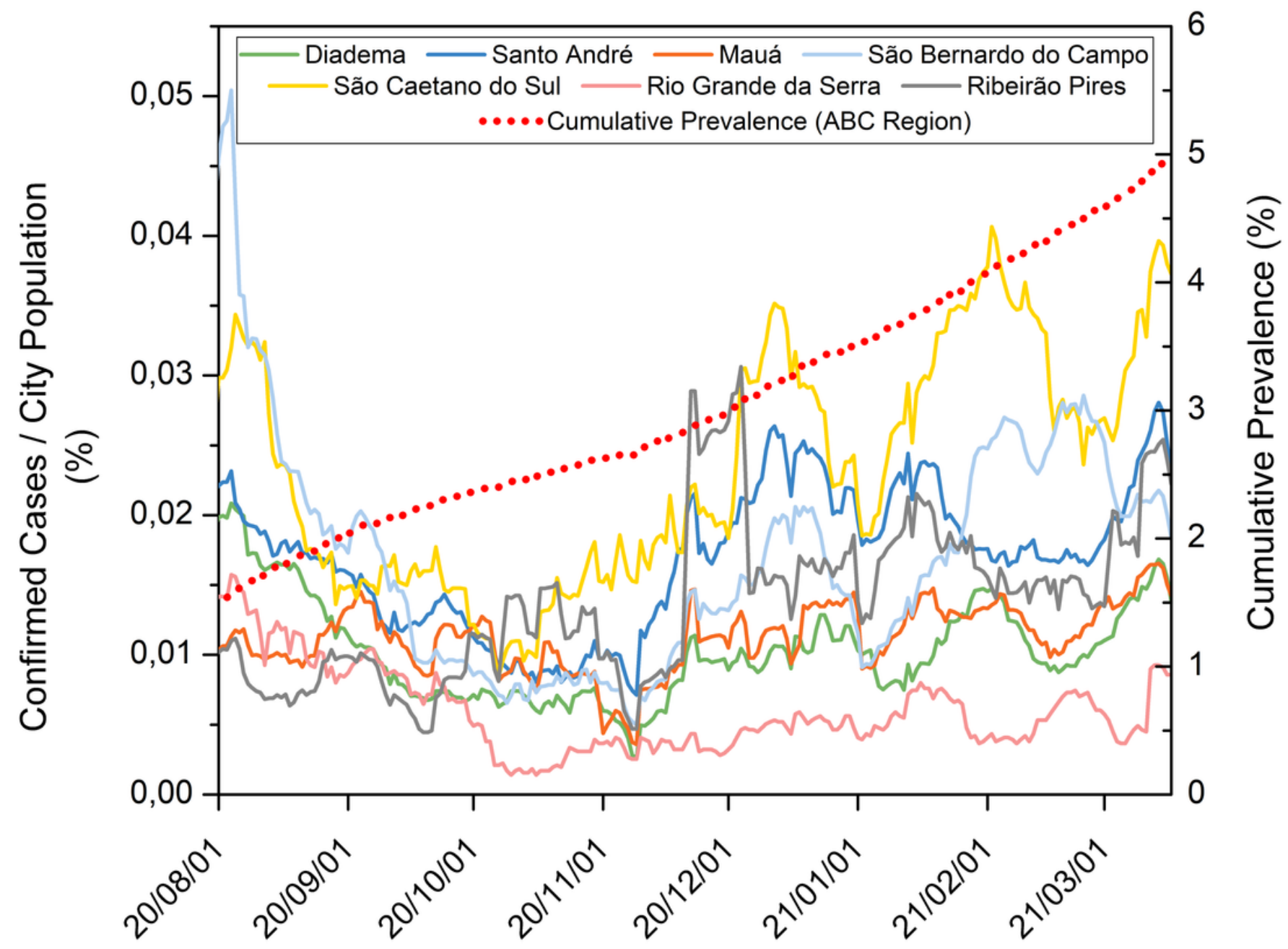

Figure 3

Epidemiological/clinical data on COVID-19 in the ABC Region. Data source:

https://ondetemcoronavirus.ufabc.edu.br/. 


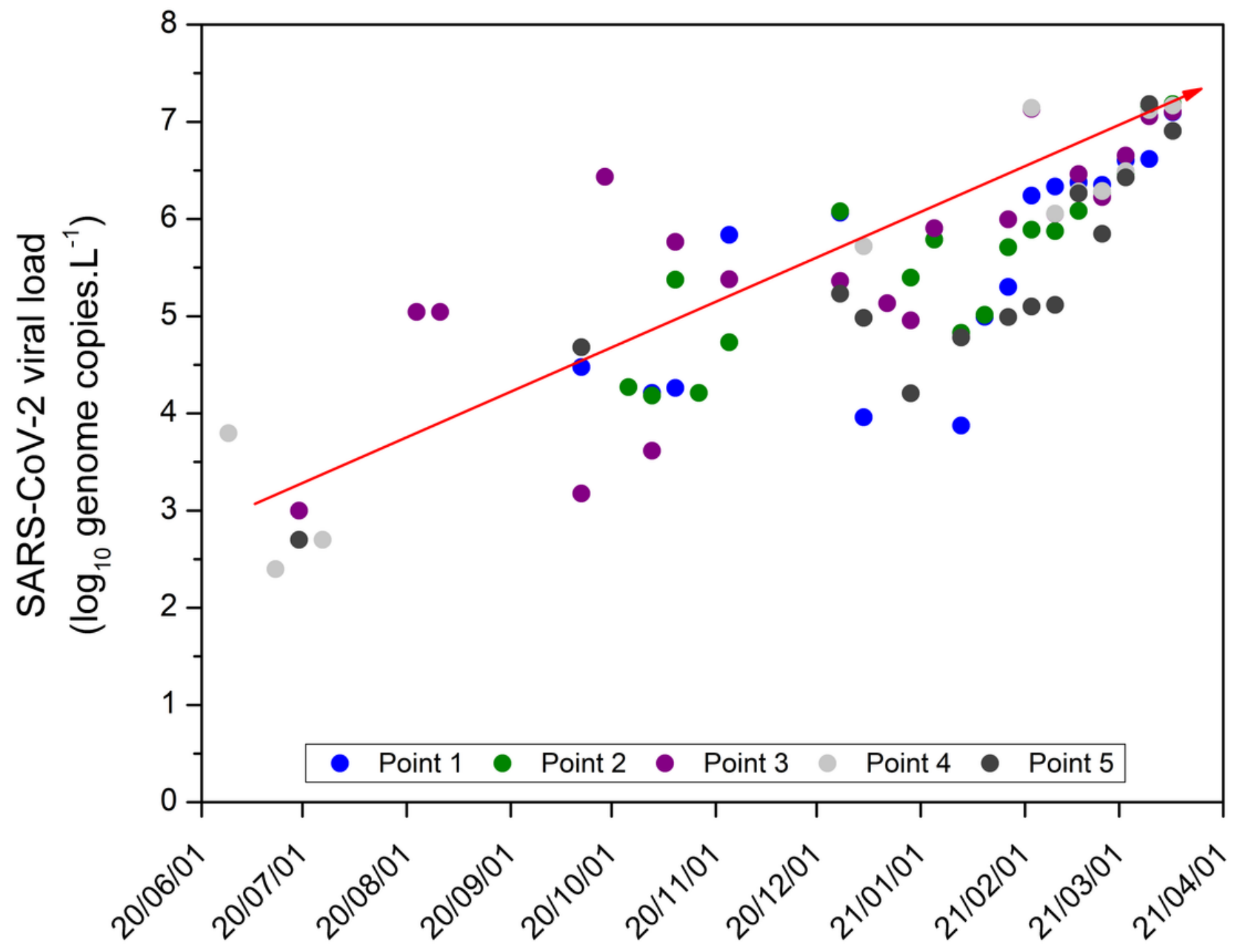

Figure 4

SARS-CoV-2 RNA concentrations (N1 assay) for the five sampling points. 


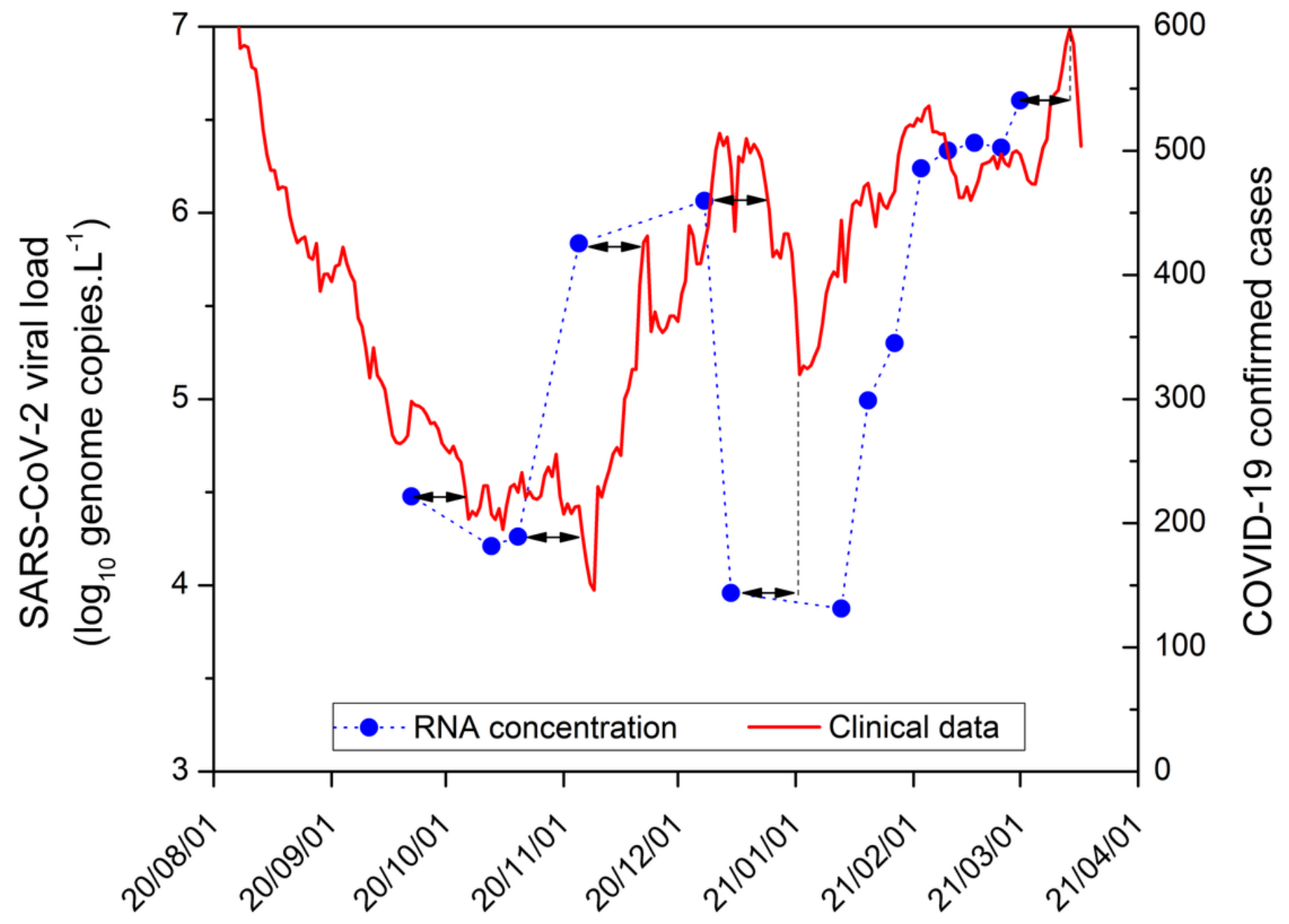

Figure 5

SARS-CoV-2 viral load (N1 assay) at Point 1 (WWTP ABC) in relation to the clinical data on COVID-19 in the $A B C$ Region.

\section{Supplementary Files}

This is a list of supplementary files associated with this preprint. Click to download.

- Supplementaryinformation.docx 